\title{
Maternal taurine supplementation in rats partially prevents the adverse effects of early-life protein deprivation on $\beta$-cell function and insulin sensitivity
}

\author{
Christine Tang ${ }^{1}$, Kelly Marchand ${ }^{4}$, Loretta Lam ${ }^{1}$, Victoria Lux-Lantos ${ }^{5}$, Sandra M Thyssen ${ }^{4}$, \\ June Guo ${ }^{1}$, Adria Giacca ${ }^{1,2,3}$ and Edith Arany ${ }^{4}$ \\ Departments of ${ }^{1}$ Physiology, ${ }^{2}$ Medicine and ${ }^{3}$ Institute of Medical Science, University of Toronto, Toronto, Ontario, \\ Canada, ${ }^{4}$ Departments of Medicine and Pathology, Lawson Health Research Institute, University of Western Ontario, \\ St Joseph's Health Care, 268 Grosvenor Street, London, Ontario, Canada N6A 4V2, ${ }^{5}$ Instituto de Biologia y Medicina \\ Experimental - CONICET, Buenos Aires, Argentina
}

Correspondence should be addressed to E Arany; Email: edith.arany@lawsonresearch.com

\begin{abstract}
Dietary protein restriction during pregnancy and lactation in rats impairs $\beta$-cell function and mass in neonates and leads to glucose intolerance in adult offspring. Maternal taurine (Tau) supplementation during pregnancy in rats restores $\beta$-cell function and mass in neonates, but its long-term effects are unclear. The prevention of postnatal catch-up growth has been suggested to improve glucose tolerance in adult offspring of low-protein (LP)-fed mothers. The objective of this study was to examine the relative contribution of $\beta$-cell dysfunction and insulin resistance to impaired glucose tolerance in 130-day-old rat offspring of LP-fed mothers and the effects of maternal Tau supplementation on $\beta$-cell function and insulin resistance in these offspring. Pregnant rats were fed i) control, ii) LP, and iii) LP + Tau diets during gestation and lactation. Offspring were given a control diet following weaning. A fourth group consisting of offspring of LP-fed mothers, maintained on a LP diet following weaning, was also studied (LP-all life). Insulin sensitivity in the offspring of LP-fed mothers was reduced in females but not in males. In both genders, LP exposure decreased $\beta$-cell function. Tau supplementation improved insulin sensitivity in females and $\beta$-cell function in males. The LP-all life diet improved $\beta$-cell function in males. We conclude that i) maternal Tau supplementation has persistent effects on improving glucose metabolism ( $\beta$-cell function and insulin sensitivity) in adult rat offspring of LP-fed mothers and ii) increasing the amount of protein in the diet of offspring adapted to a LP diet after weaning may impair glucose metabolism ( $\beta$-cell function) in a gender-specific manner.

Reproduction (2013) 145 609-620
\end{abstract}

\section{Introduction}

Type 2 diabetes is a prevalent health concern worldwide and has been predicted to affect more than 438 million people by the year 2030 (Shaw et al. 2010). A perinatal origin of adult disease has been suggested to contribute to the rapid rise in type 2 diabetes. This has been supported by epidemiological and animal studies, which have shown a strong relationship between poor fetal growth and subsequent development of obesity and type 2 diabetes in adult life (Hales \& Barker 1992).

Protein restriction (low-protein (LP), 8\%) during pregnancy and lactation in rats has been used extensively to investigate the role of fetal environment to determine future susceptibility to adult disease.

Offspring of rats fed a LP diet during gestation and lactation have lower body weights and altered structure and function of the fetal endocrine pancreas (Snoeck et al. 1990, Dahri et al. 1991) with reduced islet size and pancreatic insulin content (Snoeck et al. 1990, Petrik et al. 1999, Boujendar et al. 2002), reduced islet cell proliferation, increased islet cell apoptosis (Snoeck et al. 1990, Petrik et al. 1999), and altered islet vascularization (Snoeck et al. 1990). Previously, we suggested that the increase in $\beta$-cell apoptosis and decrease in neogenesis are due to the decrease in insulin-like growth factor 2 (IGF2) expression (Petrik et al. 1999). Moreover, the insulin-secretory capacity of fetal $\beta$-cells in response to secretagogues from LP-fed rat mothers is also significantly reduced (Dahri et al. 1991, Cherif et al. 1998). Despite changing to a control diet after birth or after weaning, $\beta$-cell dysfunction (as shown by a lower insulin response after a glucose challenge) persists into late adulthood in males (Dahri et al. 1995, Minana-Solis Mdel \& Escobar 2008) and females (Dahri et al. 1995), suggesting that events in the fetal and early postnatal growth periods can predispose subjects to glucose intolerance and diabetes in adult life. 
LP exposure during pregnancy and lactation affects insulin sensitivity in the adult offspring. Male and female offspring of LP-fed mothers have been reported to exhibit altered hepatic expression of enzymes involved in the regulation of glucose homeostasis (Desai et al. 1997). LP exposure during early life has also been shown to affect the expression and activation of key proteins involved in the insulin signaling cascade in peripheral tissues in adult males (Ozanne et al. 1997, 2003, Garcia-Souza et al. 2008, Chamson-Reig et al. 2009) and females (Fernandez-Twinn et al. 2005).

Although both $\beta$-cell dysfunction and insulin resistance contribute to diabetes, it is unclear which is prevalent in this model of dietary restriction. Previously, our laboratory observed for the first time that at 130 days of age (young adulthood), LP offspring of both sexes showed signs of impaired glucose tolerance and this deterioration was gender specific. Specifically, males exhibited decreased insulin sensitivity as calculated by the homeostatic model assessment (HOMA) index, while females exhibited reduced $\beta$-cell mass (Chamson-Reig et al. 2009).

Moreover, maternal protein deprivation leads to alteration in the plasma amino acid profiles in both the mother and fetus. Taurine (Tau), a non-essential amino acid, has been found to be markedly reduced by a LP diet, especially in fetal serum (Reusens et al. 1995). Tau is a sulfur-containing amino acid that is present in high concentrations in tissues, but is not incorporated into proteins or used for energy production. It has been found to be important for normal fetal development (Sturman 1993, Lourenco \& Camilo 2002) and is dependent on placental transfer from the mother (Huxtable 1992). Tau has trophic effects in the developing endocrine pancreas. The physiological role of Tau is not fully understood, but Tau is known to be involved in a variety of biological processes such as osmoregulation, oxidative stress inhibition, and bile salt formation (Bouckenooghe et al. 2006).

Previously, we also demonstrated that maternal Tau supplementation in LP diets prevents the loss of $\beta$-cell mass by enhancing $\beta$-cell proliferation, increasing IGF2 expression and islet vascularization, and decreasing $\beta$-cell apoptosis in fetal islets (Boujendar et al. 2002, 2003). Whether this beneficial effect of Tau persists until adulthood is unclear. One study has shown that maternal Tau supplementation restores insulin response to a glucose challenge in 11-week-old female offspring of LP-fed dams, although unnecessary supplementation of Tau to control animals could have detrimental effects including weak glucose intolerance (Merezak et al. 2004). The same authors have shown that maternal and fetal plasma glucose levels are not altered by maternal protein restriction; however, plasma amino acid profiles are perturbed, and plasma concentration of Tau and its synthesis are decreased in both the mother and fetus (Reusens et al. 1995). Supplementation of maternal LP diet with Tau $(2.5 \%$ in the drinking water as in the present study) normalizes its concentration in the fetal plasma (Sturman 1993, Lourenco \& Camilo 2002). A recent study has demonstrated that the addition of Tau to a similar model of maternal protein restriction prevents decreased pancreatic islet mass and reduced insulinsecretory responses to glucose load, possibly through the prevention of mitochondrial dysfunction in the $\beta$-cells (Lee et al. 2011).

In addition to fetal growth restriction, it has been suggested that postnatal catch-up growth due to changes in the environment (changes to the diet) following growth restriction may increase the susceptibility to diseases such as type 2 diabetes and hypertension (Forsen et al. 2000, Hales \& Barker 2001). One theory has proposed to explain these findings through the predictive adaptive response (Gluckman \& Hanson 2006), which states that the fetus is constantly interpreting the environment created by the maternal milieu and placental function and predicts the environment into which it is likely to be born. However, this prediction can be detrimental when inadequate or excessive nutrients are present following birth. In the present study, in adult offspring at 130 days of age, we i) investigated the site of glucose homeostasis deterioration by maternal protein deprivation using the gold standard hyperinsulinemiceuglycemic clamp (insulin sensitivity) and hyperglycemic clamp ( $\beta$-cell function), ii) investigated whether Tau supplementation during gestation and lactation can prevent the adverse effects of maternal LP diet on glucose metabolism ( $\beta$-cell function and insulin sensitivity), iii) determined whether maintaining protein restriction throughout life (i.e. maintaining a LP diet after weaning in the offspring) has beneficial effects, and iv) determined whether all of these effects $(1,2$, and 3$)$ are gender specific.

\section{Results}

In both tables and figures, letters indicate significant differences between the groups - $a$, LP vs CONT; $b$, LP+Tau vs CONT; c, LP-all life vs CONT; $d$, LP+Tau vs LP; e, LP-all life vs LP; and f, LP+Tau vs LP-all life.

Table 1 Body weight, fasting plasma glucose, and fasting plasma insulin levels (means \pm S.E.M.) in 130-day-old male rats.

\begin{tabular}{lcccc}
\hline & $\begin{array}{c}\text { CONT } \\
(n=7)\end{array}$ & $\begin{array}{c}\text { LP } \\
(n=7)\end{array}$ & $\begin{array}{c}\text { LP+Tau } \\
(n=9)\end{array}$ & $\begin{array}{c}\text { LP-all life } \\
(n=10)\end{array}$ \\
\hline Body weight (g) & $590 \pm 32$ & $466 \pm 19^{\mathrm{a}}$ & $509 \pm 15^{\mathrm{b}, \mathrm{d}}$ & $445 \pm 13^{\mathrm{c}}$ \\
$\begin{array}{c}\text { Fasting plasma } \\
\text { glucose (mmol/l) }\end{array}$ & $7.3 \pm 0.3$ & $6.3 \pm 0.2^{\mathrm{a}}$ & $6.8 \pm 0.1$ & $7.1 \pm 0.3$ \\
$\begin{array}{c}\text { Fasting plasma } \\
\text { insulin (pmol/l) }\end{array}$ & $384 \pm 46$ & $231 \pm 64^{\mathrm{a}}$ & $221 \pm 49.5^{\mathrm{b}}$ & $205 \pm 32^{\mathrm{c}}$ \\
\hline
\end{tabular}

a, LP vs CONT; b, LP + Tau vs CONT; c, LP-all life vs CONT; and d, LP+ Tau vs LP. 
Table 2 Body weight, fasting plasma glucose, and fasting plasma insulin levels (means \pm S.E.M.) in 130-day-old female rats.

\begin{tabular}{lcccc}
\hline & $\begin{array}{c}\text { CONT } \\
(n=7)\end{array}$ & $\begin{array}{c}\text { LP } \\
(n=7)\end{array}$ & $\begin{array}{c}\text { LP+Tau } \\
(n=9)\end{array}$ & $\begin{array}{c}\text { LP-all life } \\
(n=10)\end{array}$ \\
\hline Body weight $(\mathrm{g})$ & $328 \pm 10$ & $273 \pm 8^{\mathrm{a}}$ & $293 \pm 13^{\mathrm{b}, \mathrm{d}}$ & $265 \pm 9^{\mathrm{c}}$ \\
$\begin{array}{c}\text { Fasting plasma } \\
\text { glucose }(\mathrm{mmol} / \mathrm{l})\end{array}$ & $6.6 \pm 0.1$ & $6.8 \pm 0.4$ & $7.1 \pm 0.3$ & $6.7 \pm 0.5$ \\
$\begin{array}{c}\text { Fasting plasma } \\
\text { insulin (pmol/l) }\end{array}$ & $154 \pm 18$ & $159 \pm 15$ & $135 \pm 21$ & $163 \pm 6$ \\
\hline
\end{tabular}

a, LP vs CONT; b, LP+ Tau vs CONT; c, LP-all life vs CONT; and d, LP+ Tau vs LP.

\section{Body weight and blood parameters}

We conducted a two-way ANOVA to determine the effects of sex and treatments on body weight and fasting glucose and insulin levels, and as expected, both male and female offspring of all the LP-treated groups had a significantly lower body weight than the control (CONT) group (a, $P<0.01 ; \mathrm{b}, P<0.05$; and $\mathrm{c}, P<0.001$ ). Supplementation with Tau during gestation and lactation partially prevented the reduced body weight associated with a LP diet $(\mathrm{d}, P<0.05)$ in both females and males (Tables 1 and 2). In males, fasting glucose levels were significantly lower in the LP rats $(\mathrm{a}, P<0.01)$. Fasting insulin levels were lower in all the LP-treated groups than in the CONT group ( $a, b$ and $c, P<0.05)$. In females, no differences were observed in fasting blood glucose or insulin levels (Tables 1 and 2). There was no interaction between sex and treatments for any of the measures.

\section{Hyperinsulinemic-euglycemic clamp}

In males, basal glucose levels were significantly decreased in the LP group vs the CONT and LP-all life groups (a and e, $P<0.05$; see Fig. 1 for the protocol scheme). No significant differences in plasma glucose levels were observed during the clamp (Fig. 2A).
In females, plasma glucose levels were not different between the treatments during either the basal period or the clamp (Fig. 2B). Glucose infusion (Ginf) rate during the last $30 \mathrm{~min}$ of the $90 \mathrm{~min}$ of the hyperinsulinemiceuglycemic clamp is an indicator of whole-body insulin sensitivity. In males, the Ginf showed no significant differences in any of the groups (Fig. 2C). In females, the Ginf was significantly increased in the LP + Tau group vs the LP and LP+Tau groups vs the LP-all life group (d and $\mathrm{f}, P<0.01$; Fig. 2D). In males, the LP+Tau and LP-all life groups had significantly lower basal insulin levels than the control group ( $b$ and $c, P<0.05$; Fig. 2E). No changes in insulin levels were observed in females during the basal period and the clamp in any of the groups (Fig. 2F).

During the clamp, plasma insulin levels were markedly elevated in all the groups due to insulin infusion and no significant differences were observed between the groups.

During the basal period, endogenous glucose production (EGP) was equal to glucose utilization and was lower in the LP group than in the other groups in males (a and e, $P<0.01 ; \mathrm{d}, P<0.05$; Fig. $3 \mathrm{~A}$ ). Females did not show differences between the groups in the basal state (Fig. 3B).

During the clamp, we were able to maintain low level $(<30 \%)$ fluctuation in plasma glucose-specific activity from the basal state, which prevented significant error in the calculation of glucose production. Hepatic insulin sensitivity is measured as the capacity of insulin to suppress EGP in the basal state. In males, LP exposure tended to decrease the ability of insulin to suppress EGP from basal $(43 \pm 11 \%$ in the CONT group vs $24 \pm 14 \%$ in the LP group), whereas this tendency was not observed in the other groups (LP+Tau and LP-all life groups; Fig. 3A). In females, no differences in EGP were observed between the groups during the clamp (Fig. 3B).

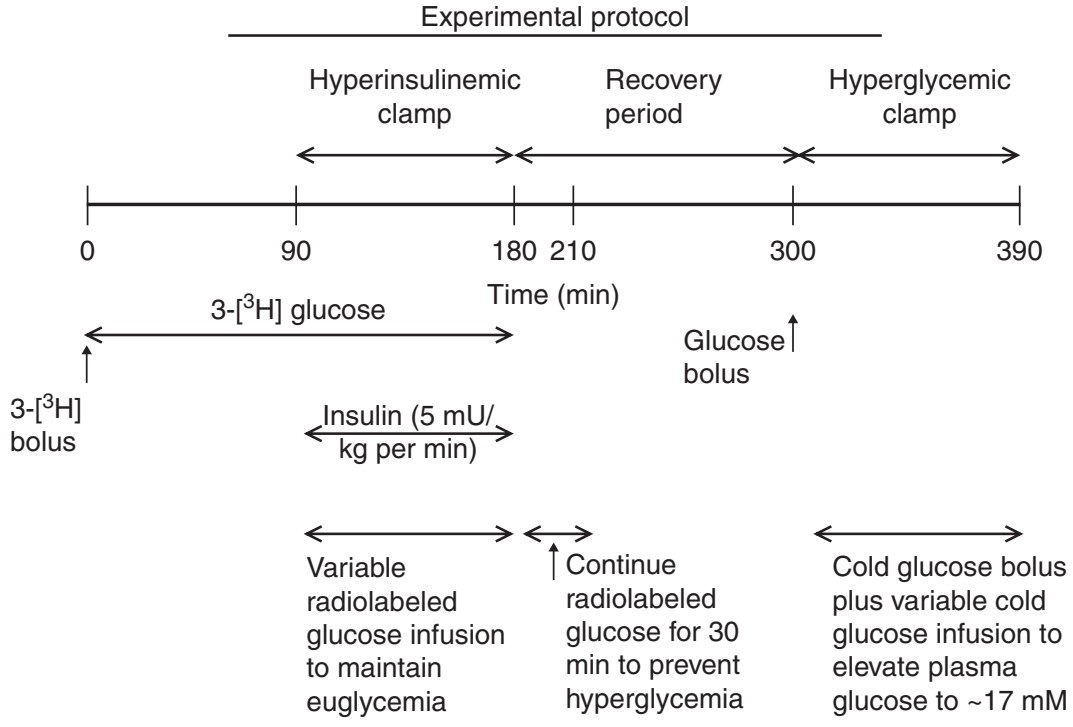

Figure 1 Schematic of the experimental protocol. The details are given in the Materials and Methods section. Briefly, the hyperinsulinemic clamp with glucose tracer methodology was performed to determine whole-body, hepatic, and peripheral insulin sensitivity, whereas the hyperglycemic clamp was performed to determine pancreatic $\beta$-cell secretory function. 


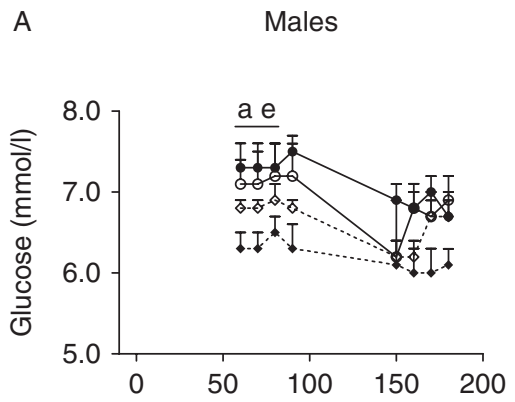

C
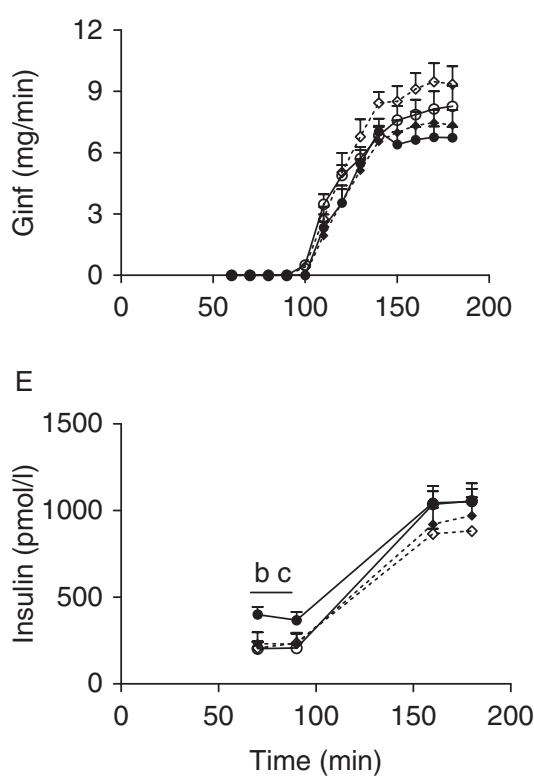

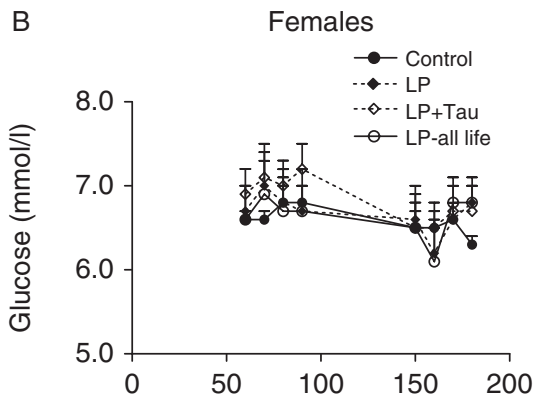

D

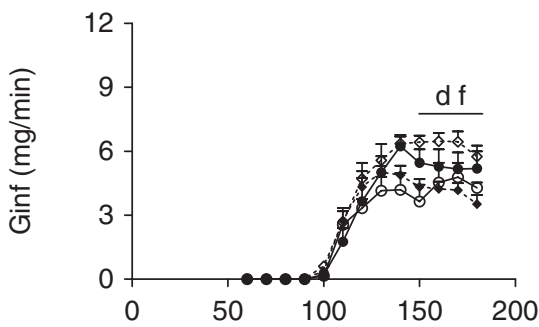

$\mathrm{F}$

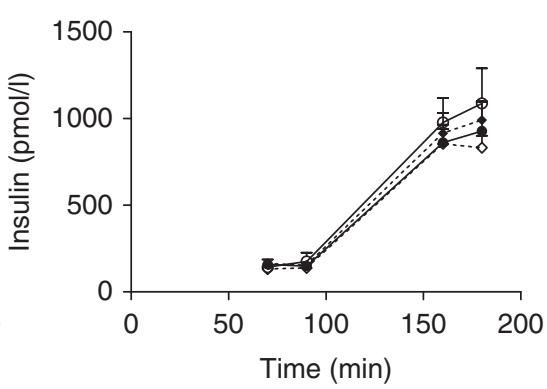

Figure 2 Plasma glucose levels, glucose infusion rate (Ginf), and plasma insulin levels during the hyperinsulinemic-euglycemic clamp in males (A, C and E) and females (B, D and F) at 130 days of age. Offspring of Wistar rats born to mothers fed a control diet (CONT), a low-protein (LP) diet, or a LP diet with taurine (LP+Tau) were used in the study. Pups were fed a normal chow diet following weaning. A subset of LP rats was maintained on a LP diet following weaning (LP-all life). In males, basal plasma glucose levels were reduced in the LP group vs the $C$ group and the LP group vs the LP-all life group (A). The Ginf showed no significant differences between the groups (C). Basal plasma insulin levels were significantly reduced in the $\mathrm{LP}+$ Tau and LP-all life groups vs the $\mathrm{C}$ group (E). In females, no difference in basal or clamp glucose levels was observed between the groups (B). The Ginf was significantly increased in the LP+Tau group vs the LP group and the LP+ Tau group vs the LP-all life group (D). Basal and clamp insulin levels were not different between the groups $(F)$. Data are means \pm S.E.M. Number of rats studied $(n)=6-10$ per group. The line indicates a period of time where significances were found. a, LP vs CONT $(P<0.05)$; b, LP+ Tau vs CONT $(P<0.05)$; c, LP-all life vs CONT $(P<0.05)$; d, LP+Tau vs LP $(P<0.01)$; e, LP-all life vs LP $(P<0.01)$; and $\mathrm{f}$, LP-all life vs LP+ Tau $(P<0.01)$.
In LP+Tau males, glucose utilization during the clamp was significantly higher $(b, P<0.01)$ than that in the CONT group and was also higher $(f, P<0.05)$ than that in the LP-all life group (Fig. 3C). In females, there was a significant decrease in glucose utilization during the clamp in the LP group vs the CONT group $(\mathrm{a}, P<0.01)$. In the $\mathrm{LP}+$ Tau group, this decrease was completely prevented (d, $P<0.05$; Fig. 3D), whereas the LP-all life group was not different from the LP group (e, $P>0.05)$.

The sensitivity index (M/I (glucose metabolism (M) divided by plasma insulin (I)) index) was calculated by dividing the Ginf by plasma insulin levels during the last $30 \mathrm{~min}$ of the hyperinsulinemic-euglycemic clamp. In male offspring, the two-way ANOVA showed that the M/I index was not significantly different from that of the CONT group in both the LP and LP-all life groups. Interestingly, the $M / I$ index was significantly increased in the LP+Tau group vs the CONT group (b, $P<0.01$; Fig. 4A). In females, the $M / I$ index was significantly decreased in the LP and LP-all life groups than in the $L P+$ Tau group $(d, P<0.01 ; f, P<0.05)$, suggesting that maternal supplementation with Tau restored the $M / I$ index to levels comparable to those observed in the CONT group (Fig. 4B). The difference between the LP and LP-all life groups and the CONT group did not reach significance $(P>0.05)$. In females, the $M / I$ index was not improved in the LP-all life group vs the LP group.

\section{Effect of $L P \pm$ Tau supplementation on $\beta$-cell function}

Plasma glucose levels during the basal period and the clamp were not significantly different between the groups in males and also in females (Fig. 5A and B). The Ginf rate indicates whether circulating insulin levels can adequately compensate for insulin resistance. In LP males, a lower Ginf was required to clamp glucose at $17 \mathrm{mM}$, indicating that circulating insulin levels were inadequate to compensate for insulin resistance (a, $P<0.05)$. Supplementation with Tau restored the Ginf (d, $P<0.05$; Fig. 5C). In females, when compared with the CONT group, the LP-all life group exhibited lower glucose utilization during the clamp $(C, P<0.05)$ and the LP group tended to have a lower Ginf $(a, P<0.1)$. Moreover, supplementation with Tau was not different from the control (Fig. 5D). 

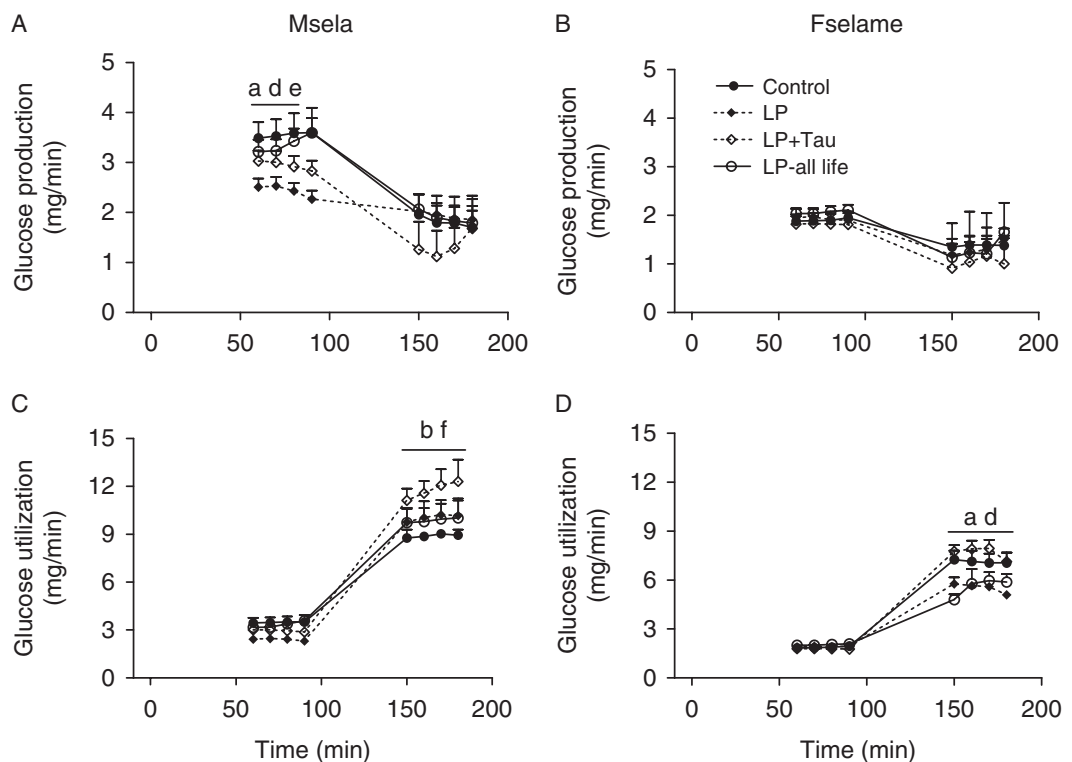

Figure 3 Endogenous glucose production (EGP) and peripheral glucose utilization during the hyperinsulinemic-euglycemic clamp in males (A and C) and females (B and D) at 130 days of age. Offspring of Wistar rats born to mothers fed a control diet (CONT), a low-protein (LP) diet, or a LP diet with taurine ( $\mathrm{LP}+\mathrm{Tau}$ ) were used in the study. Pups were fed a normal chow diet following weaning. A subset of LP rats was maintained on a LP diet following weaning (LP-all life). During the basal period, endogenous glucose production (EGP) was lower in the LP group than in the other groups in males (a, e and d) (A). Females did not show differences between the groups in the basal state (B). In males, during the clamp, glucose utilization was significantly increased in the LP+Tau group than in the CONT and LP-all life groups (b and d) (C). In females, there was a significant decrease in glucose utilization during the clamp in the LP group vs the CONT group; this decrease was completely prevented in the LP+Tau group, whereas the LP-all life group was not different from the LP group (a and d) (D). Data are means \pm S.E.M. Number of rats studied $(n)=6-10$ per group. The line indicates a period of time where significances were found. a, LP vs CONT $(P<0.01)$; b, LP+Tau vs CONT $(P<0.01)$; d, LP+Tau vs LP $(P<0.05)$; e, LP-all life vs LP $(P<0.01)$; and $\mathrm{f}$, LP+Tau vs LP-all life $(P<0.05)$.

In males, basal insulin levels were significantly lower in all the LP-treated groups than in the CONT group (a, b and c, $P<0.05$; Fig. 6A). Basal C-peptide levels were significantly lower in all the LP groups $(\mathrm{a}, \mathrm{b}$ and $\mathrm{c}$, $P<0.05$; Fig. 6C). In females, basal insulin and C-peptide levels were not significantly different between the groups (Fig. 6B and D).

To assess first-phase insulin secretion, a bolus of $50 \%$ glucose was injected at the start of the hyperglycemic clamp to elevate plasma glucose levels to $17 \mathrm{mM}$. Plasma samples for insulin and C-peptide measurements were taken at 2, 5, and $10 \mathrm{~min}$. In males, all LP treatments elicited a significantly lower first-phase insulin response to glucose compared with the CONT treatment $(\mathrm{a}, \mathrm{b}$ and $\mathrm{c}, \mathrm{P}<0.01$; Fig. $6 \mathrm{~A})$. During this phase, C-peptide levels in the LP group were significantly lower than those in the CONT group (a, $P<0.01$; Fig. 6C). The LP+Tau and LP-all life groups were not significantly different from the LP group, suggesting that these treatments did not prevent the impairing effect of maternal LP on first-phase insulin response in adult offspring (Fig. 6A and C). In females, all treatment groups had similar first-phase insulin and C-peptide responses. No statistical differences were observed (Fig. 6B and D).

To assess second-phase insulin secretion, plasma insulin and C-peptide levels were measured during the hyperglycemic clamp. In males, all the LP groups had significantly lower insulin levels than the CONT group ( $\mathrm{a}, \mathrm{b}$ and $\mathrm{c}, \mathrm{P}<0.01$; Fig. 6A). C-peptide levels in the LP group were significantly lower than those in the CONT group (a, $P<0.01$; Fig. 6C). The LP+Tau group had insulin levels similar to those in the LP group, whereas C-peptide levels in the LP-all life group were similar to those in the CONT group (Fig. 6A and C). In females, insulin and C-peptide levels were lower in the LP-all life group vs the CONT group (c, $P<0.01)$. LP and LP+Tau levels were lower, but not statistically significant vs CONT (Fig. 6B and D).

The C-peptide-to-insulin ratio is an index of insulin clearance. In neither males nor females, the C-peptideto-insulin ratio was significantly different between the groups (data not reported).

The disposition index (DI), which represents the ability of the $\beta$-cell to compensate for insulin resistance, was calculated by multiplying the sensitivity index calculated from the hyperinsulinemic-euglycemic clamp (Ginf divided by insulin during the last $30 \mathrm{~min}$ of the clamp) by C-peptide levels (measured during the hyperglycemic clamp). The insulin sensitivity index calculated from the hyperglycemic clamp (Ginf/insulin) was not used to calculate the DI, since it is well known that insulin sensitivity assessed by the hyperinsulinemiceuglycemic clamp is a more accurate measure. In males, the two-way ANOVA showed that the DI was lower in 

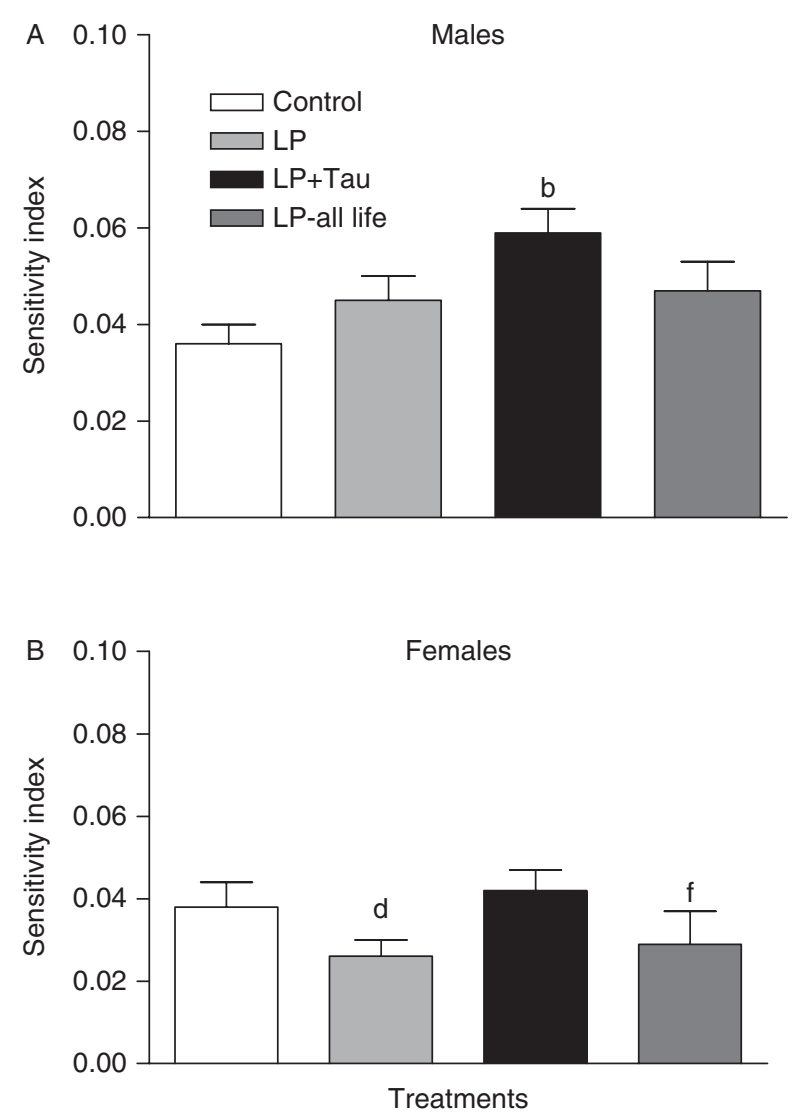

Figure 4 Sensitivity index calculated during the hyperinsulinemiceuglycemic clamp in males (A) and females (B) at 130 days of age. Sensitivity index ( $\mathrm{SI}$ ) was calculated as glucose infusion rate (Ginf) divided by plasma insulin during the last $30 \mathrm{~min}$ of the hyperinsulinemic-euglycemic clamp. Units of sensitivity index are milligram per minute glucose infusion per picomole per liter insulin. Offspring of Wistar rats born to mothers fed a control diet (CONT), a low-protein (LP) diet, or a LP diet with taurine (LP+Tau) were used in the study. Pups were fed a normal chow diet following weaning. A subset of LP rats was maintained on a LP diet following weaning (LP-all life). Data are means \pm s.E.M. Number of rats studied $(n)=6-10$ per group. b, LP + Tau vs CONT $(P<0.01)$; d, LP+Tau vs LP $(P<0.01)$; and $\mathrm{f}$, LP-all life vs $\mathrm{LP}+\mathrm{Tau}(P<0.05)$.

the LP group vs the CONT group $(\mathrm{a}, P<0.001)$ and higher in the LP+Tau and LP-all life groups than in the LP group ( $d$ and e, $P<0.001 ;$ Fig. 7A). In females, the DI was significantly lower in all the LP-treated groups than in the CONT group (a and $\mathrm{c}, P<0.001 ; \mathrm{b}$, $P<0.05$; Fig. 7B).

\section{Discussion}

In the present study, using the hyperinsulinemiceuglycemic and hyperglycemic clamps in males and females, we investigated whether i) LP exposure during fetal and neonatal life affects insulin sensitivity and/or $\beta$-cell function in adult offspring, ii) maternal supplementation with Tau in early life protects against the adverse effects of protein deprivation on insulin sensitivity and/or $\beta$-cell function at 130 days, and iii) LP exposure throughout life affects insulin sensitivity and/or $\beta$-cell function in 130-day-old adult offspring.

Previous studies have demonstrated that LP exposure during early life can alter insulin sensitivity in adult male (Ozanne et al. 1996, 2003, Shepherd et al. 1997, Sugden \& Holness 2002) and female (Merezak et al. 2004, Fernandez-Twinn et al. 2005, Chamson-Reig et al. 2009) offspring. However, whether LP exposure decreases (Sugden \& Holness 2002, Fernandez-Twinn et al. 2005, Zambrano et al. 2006) or increases (Ozanne et al. 1996, Shepherd et al. 1997, Merezak et al. 2004) insulin sensitivity is not completely clear. The increase in insulin sensitivity may result from chronic adaptation to a lower $\beta$-cell function (Sugden \& Holness 2002, Merezak et al. 2004). The effect of LP exposure on insulin sensitivity appears to be greatly dependent on the age at which the offspring are studied (Ozanne et al. 1996, 2003). Previously, our laboratory showed that at 130 days of age, male offspring of LP-fed mothers have higher fasting insulin levels and exhibit insulin resistance as calculated by the HOMA index, whereas LP females do not show changes in insulin sensitivity compared with the controls (Chamson-Reig et al. 2009). To further explore these findings, we performed the gold standard hyperinsulinemic-euglycemic clamp at 130 days of age to assess for changes in insulin sensitivity in LP offspring. In contrast to our previous findings, we observed that males fed a LP diet during gestation and lactation had decreased basal insulin and glucose levels. The reason for this discrepancy is not completely clear; however, it may that the longer duration of fasting in the present study may have affected gluconeogenesis in the LP rats due to a lack of amino acid substrates from muscle. Fetal protein malnutrition has been found previously to result in low muscle mass (Fortman et al. 2005, Rehfeldt et al. 2012). In the previous study, the hyperinsulinemic-euglycemic clamp technique was not used. Using this technique, another study performed in 20-week-old male offspring of LP-fed mothers found that whole-body insulin sensitivity was not affected, but insulin secretion during intravenous glucose tolerance test (IVGTT) was reduced, similar to the present study (Lee et al. 2011). However, in accordance with our previous study showing HOMAevaluated insulin resistance, LP males tended to show reduced suppression of EGP (hepatic insulin resistance). Since basal EGP was lower in LP male rats, the possibility cannot be excluded that the decrease in suppression may also be due to the initial reduction in basal EGP. In contrast to hepatic insulin sensitivity, peripheral insulin sensitivity as indicated by glucose utilization was reduced in LP females. The mechanisms of the sexual dimorphism involved in the observed change in insulin sensitivity with LP exposure are unclear, as alterations in components of the insulin signaling cascade in peripheral insulin-sensitive tissues have been documented in both male (Ozanne et al. 1997, 2003, Garcia-Souza 

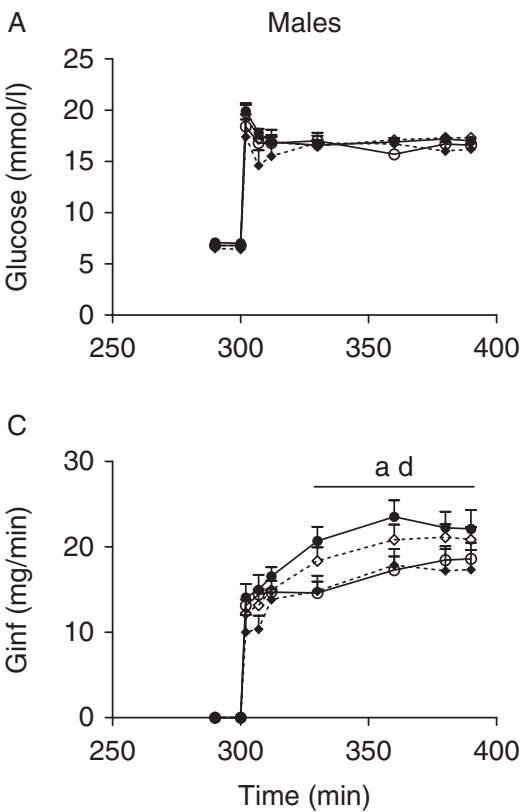

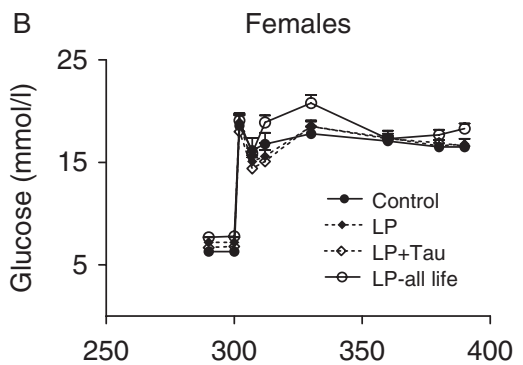

D

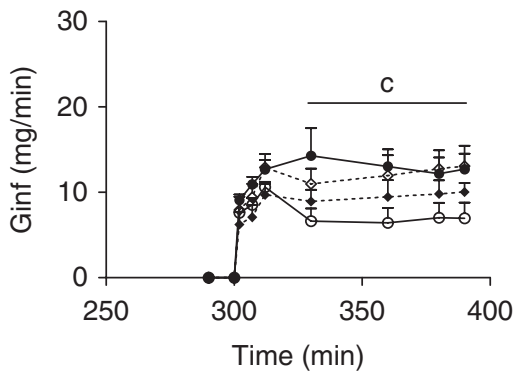

Figure 5 Plasma glucose levels and glucose infusion rate (Ginf) during the hyperglycemic clamp in males ( $A$ and $C$ ) and females (B and D) at 130 days of age. Plasma glucose levels were raised to $\sim 17 \mathrm{mM}$ in all the groups. Offspring of Wistar rats born to mothers fed a control diet (CONT), a low-protein (LP) diet, or a LP diet with taurine (LP+Tau) were used in the study. Pups were fed a normal chow diet following weaning. A subset of LP rats was maintained on a LP diet following weaning (LP-all life). In males, supplementation with Tau restored the Ginf (C). In females, when compared with the CONT group, the LP-all life group exhibited lower glucose utilization during the clamp (D). Data are means \pm S.E.M. Number of rats studied $(n)=6-10$. The line indicates a period of time where significances were found. a, LP vs CONT $(P<0.05)$; C, LP-all life vs CONT $(P<0.05)$; and d, LP+Tau vs LP $(P<0.05)$. et al. 2008, Chamson-Reig et al. 2009) and female (Fernandez-Twinn et al. 2005) offspring of LP-fed mothers.

It has been reported that a LP diet given during fetal and neonatal life induces abnormal development of the endocrine pancreas. $\beta$-Cell mass and islet size are reduced (Snoeck et al. 1990, Dahri et al. 1991, Chamson-Reig et al. 2009). Furthermore, islet cell proliferation is decreased, and islet cell apoptosis is increased (Snoeck et al. 1990, Petrik et al. 1999), effects that have been linked to decreased expression of IGFs in LP fetuses and neonates (Petrik et al. 1999). In agreement with these findings, our study has shown that a LP diet during gestation and lactation leads to offspring with a decreased insulin-secretory response to glucose. In males, the LP group had significantly lower insulin and C-peptide levels during the hyperglycemic clamp, indicating reduced insulin secretion. In females, the same tendency was observed, but it did not reach statistical significance. In vivo, it is important to evaluate insulin secretion in the context of insulin resistance, since the normal $\beta$-cell compensates for insulin resistance by increasing insulin secretion, independent of plasma glucose. In subjects with normal glucose

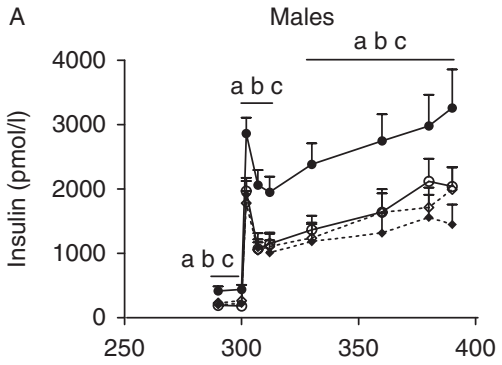

C

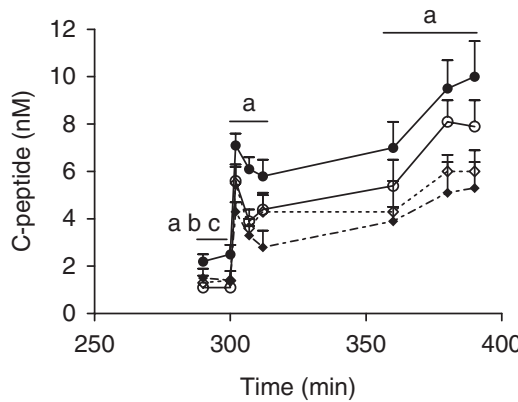

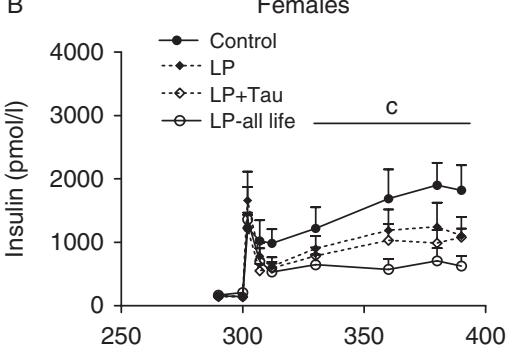

D

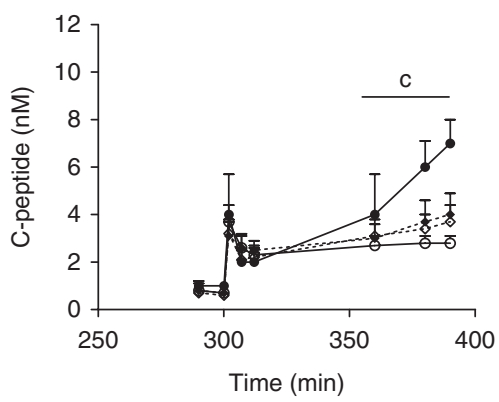

Figure 6 Plasma insulin and plasma C-peptide levels during the hyperglycemic clamp in males (A and C) and females (B and $\mathrm{D})$ at 130 days of age. Offspring of Wistar rats born to mothers fed a control diet (CONT), a low-protein (LP) diet, or a LP diet with taurine $(\mathrm{LP}+\mathrm{Tau})$ were used in the study. Pups were fed a normal chow diet following weaning. A subset of LP rats was maintained on a LP diet following weaning (LP-all life). Data are means \pm s.E.M. Number of rats studied $(n)=6-10$. The line indicates a period of time where significances were found. During the basal period (first two points on the graphs). a, LP vs CONT $(P<0.05)$; b, LP+Tau vs CONT $(P<0.05)$; and $c$, LP-all life vs CONT $(P<0.05)$. During the first and second phases of insulin secretion. a, LP vs CONT $(P<0.01)$; b, LP+Tau vs CONT $(P<0.01)$; and c, LP-all life vs CONT $(P<0.01)$. 

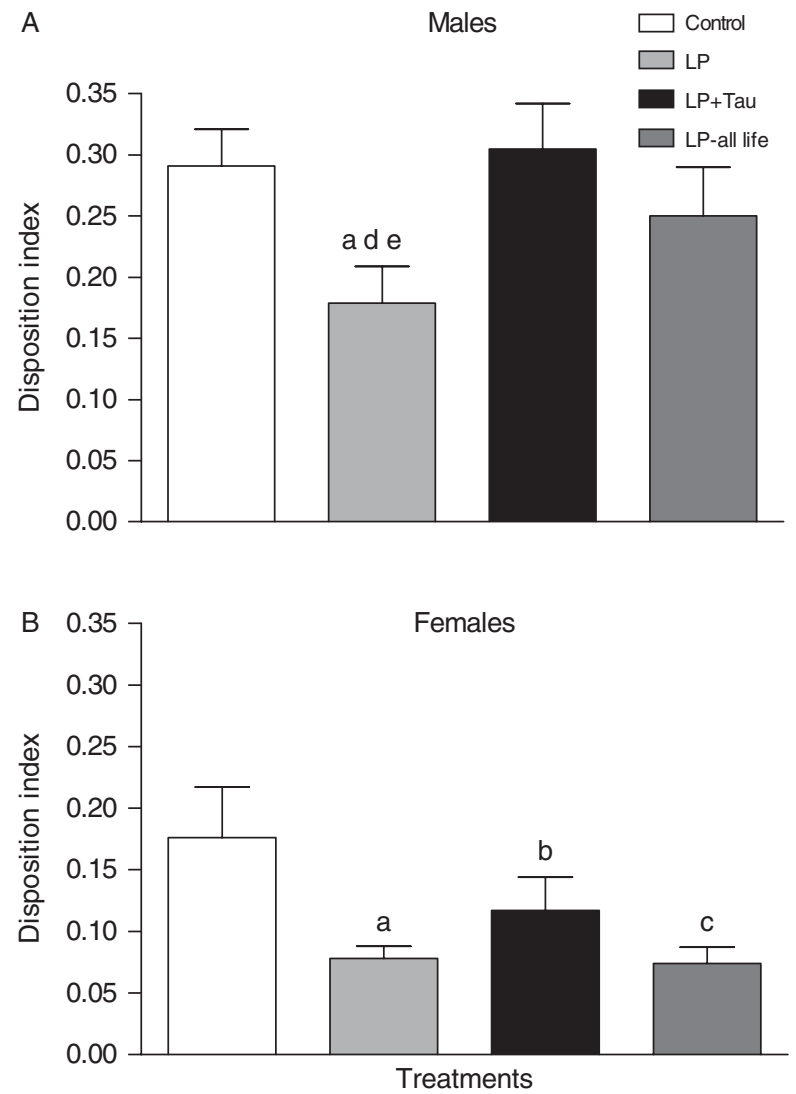

Figure 7 Disposition index in males (A) and females (B) at 130 days of age. Offspring of Wistar rats born to mothers fed a control diet (CONT), a low-protein (LP) diet, or a LP diet with taurine (LP+Tau) were used in the study. Pups were fed a normal chow diet following weaning. A subset of LP rats was maintained on a LP diet following weaning (LP-all life). Data are means \pm s.E.M. Number of rats studied $(n)=6-10$. a, LP vs CONT $(P<0.001)$; b, LP+Tau vs CONT $(P<0.05)$; c, LP-all life vs CONT $(P<0.001)$; $d$, LP+Tau vs LP $(P<0.001)$; and e, LP-all life vs $\mathrm{LP}(P<0.001)$

tolerance, insulin secretion and sensitivity are linked through a hyperbolic relationship (Bergman et al. 1981, Kahn et al. 1993), i.e. the product of insulin secretion and insulin sensitivity is a constant. This constant is known as the DI and is a measure of $\beta$-cell function (including the ability of the $\beta$-cell to compensate for insulin resistance). In females, the sensitivity index tended to be lower in the LP group than in the control group, although it did not reach statistical significance. Thus, the decrease in absolute insulin and C-peptide levels may not have reached significance in this group because of attempted compensation for insulin resistance. In males, LP exposure did not affect insulin sensitivity, which is why levels of C-peptide and insulin and the DI were all significantly reduced. The DI, which we have validated against ex vivo glucose-stimulated insulin secretion in islets (Tang et al. 2007), shows that, indeed, LP exposure during gestation and lactation leads to impaired $\beta$-cell function in both male and female adult offspring. Furthermore, we have also shown that in isolated islets the intrinsic mechanisms that regulate the secretion of both insulin and glucagon are altered in LP males at 130 days of age, due to an impaired GABA, a receptor system that maybe another contributing factor to the $\beta$-cell dysfunction observed in this study (Durst et al. 2012).

Tau is an amino acid that has been shown to be severely reduced in both maternal and fetal plasma (Reusens et al. 1995) as well as in fetal islets during maternal protein restriction. We also measured Tau levels in the pancreas by HPLC and found that, at day 1 , the offspring of LP-fed mothers had significantly lower levels of Tau $(P<0.001)$ than those of control-treated mothers and that, at 130 days, no difference was observed upon return to a control diet (Supplementary Figure 1, see section on supplementary data given at the end of this article). Tau addition to a maternal LP diet has been found to restore Tau concentration in the fetal plasma and increase $\beta$-cell mass and insulin secretion of the fetal islets (Cherif et al. 1998). Previously, our laboratory showed that maternal Tau supplementation prevents the decrease in $\beta$-cell mass (Boujendar et al. 2002) and vascularization of the fetal islets (Boujendar et al. 2003) induced by LP exposure. Importantly, previous studies by other groups had shown that Tau supplementation to a control group ( $\mathrm{C}+$ Tau group) had no effect on endocrine and $\beta$-cell mass at day 21 (fetal life) compared with the control group without Tau supplementation (Boujendar et al. 2002). Furthermore, supplementation of Tau to control rats did not change the volume and numerical densities of islet blood vessels at birth (Boujendar et al. 2003); however, unnecessary supplementation of Tau can have deleterious effects such as weak glucose intolerance when given to rats that were fed a control (20\%) protein diet (Merezak et al. 2004).

Thus, we wished to further investigate whether the beneficial effect of maternal Tau supplementation in offspring of LP-fed dams persists until adulthood. In this study, we demonstrated that in both genders, maternal Tau supplementation improves glucose metabolism in adult LP offspring. In males, Tau supplementation tended to improve hepatic insulin sensitivity (measured by \% suppression of EGP from the basal state) and increase whole-body insulin sensitivity above that of the controls. Calculation of the DI, which, as discussed above, is an in vivo measure of $\beta$-cell function, shows that Tau supplementation completely prevents the adverse effects of LP exposure on $\beta$-cell function in males. This is similar to the findings reported by Lee et al. (2011), although unlike their study, no effect of Tau on first-phase insulin secretion was observed. In females, Tau supplementation protected against the adverse effects of LP exposure on glucose utilization and overall insulin sensitivity. In males, on the other hand, Tau supplementation only protected against the adverse effects of LP exposure on $\beta$-cell function, as indicated by the DI. Thus, it appears that in males, Tau is mainly improving $\beta$-cell function, 
whereas in females, the predominant effect of Tau is in peripheral insulin-sensitive tissues.

How exactly Tau improves $\beta$-cell function and insulin sensitivity in the LP offspring is unclear. Tau has been implicated in osmoregulation, inhibition of protein phosphorylation, and calcium modulation (Huxtable 1992, Hansen 2001). Tau has also been shown to act as an antioxidant (Huxtable 1992) and has been reported to reduce reactive oxygen species in islets exposed in vivo to hyperglycemia (Tang et al. 2007) or fat (Oprescu et al. 2007). In vivo and in vitro, Tau prevents damage to fetal $\beta$-cells induced by IL1B (IL1 $\beta$ ) and NO (Merezak et al. 2001) and protects islets from cytokine toxicity in 110-day-old female offspring of LP-fed mothers (Merezak et al. 2004). Our laboratory further showed that maternal Tau supplementation delays the onset of diabetes in non-obese diabetic mice (Arany et al. 2004). Both inflammation (Hotamisligil 2006) and oxidative stress (Evans et al. 2003) have been implicated in type 2 diabetes. Thus, it is possible that LP exposure increases the susceptibility of tissues to cytokines and oxidative stress and that maternal Tau supplementation protects against these effects. Recently, it has been reported that Tau can enhance mitochondrial metabolic function. Tau may be incorporated into the mitochondria through a putative mitochondrial Tau transporter (Suzuki et al. 2002). In $\beta$-cells overexpressing uncoupling protein 2 (which is upregulated in obesity-related type 2 diabetes), Tau increases mitochondrial $\mathrm{Ca}^{2+}$ influx through the $\mathrm{Ca}^{2+}$ uniporter, leading to enhanced mitochondrial metabolic function, and the ATP:ADP ratio and restores glucose-stimulated insulin secretion (Han et al. 2004). Mitochondrial dysfunction has been linked to type 2 diabetes (Hojlund et al. 2008). Indeed, it has recently been shown that LP exposure alters mitochondrial function and Tau prevents this effect (Lee et al. 2011). Whatever be the mechanism whereby LP exposure affects $\beta$-cell function and insulin sensitivity and Tau prevents these effects, the downstream pathways mediating the phenotypic alterations should involve epigenetic mechanisms due to the persistence of these effects. Recently, it has been shown that maternal LP diet decreases HNF4a expression levels in islets of offspring via epigenetic modifications (Sandovici et al. 2011).

In addition to fetal growth restriction, it has been suggested that postnatal catch-up growth following growth restriction may increase susceptibility to some diseases, such as cardiovascular diseases and metabolic syndrome (Forsen et al. 2000, Hales \& Barker 2001). The effect of postnatal catch-up growth on glucose metabolism is unclear. One study has reported that 20-week-old male offspring of LP-fed mothers maintained on a LP diet were more insulin sensitive than offspring maintained on a normal diet following weaning (Sugden \& Holness 2002), suggesting a possible detrimental effect of postnatal catch-up growth. No differences in insulin secretion and action were reported in females at the same age (Sugden \& Holness 2002). Consistent with this report, we demonstrated herein that increasing the amount of protein in the diet (the LP group vs the LP-all life group) had detrimental effects on glucose metabolism in males but not in females. In males, LP-all life exposure had a tendency to increase hepatic insulin sensitivity and increase C-peptide levels in response to glucose during the hyperglycemic clamp compared with LP exposure. Calculation of the DI demonstrates that LP-all life exposure in males can significantly improve $\beta$-cell function. The reasons for this sexual dimorphism are still unclear.

In summary, our study demonstrates that i) early-life protein restriction impairs glucose metabolism in both male and female adult offspring; however, in males, it mainly affects $\beta$-cell function, whereas in females, both $\beta$-cell function and insulin sensitivity (peripheral) are affected; ii) maternal supplementation of Tau has a persistent effect in this model of early-life protein restriction; and iii) increase in the protein content of the diet after weaning may aggravate $\beta$-cell dysfunction induced by early LP deprivation in male offspring.

\section{Materials and Methods}

\section{Animals}

Virgin female Wistar rats were caged with males overnight. Copulation was verified the next morning by the presence of a vaginal plug. Midnight was considered as day 0 of gestation. Pregnant mothers were fed i) a $20 \%$ protein diet, which is the control diet (CONT); ii) an 8\% LP diet; or iii) an 8\% LP diet supplemented with $2.5 \%$ (w/v) Tau (Sigma) (LP+Tau) in drinking water. The diets were given throughout gestation and lactation. Following weaning, all offspring were fed a normal $20 \%$ protein diet, with the exception of the iv) LP-all life group, which continued to be fed the $8 \%$ LP diet following weaning. In the LP diet, the balance of calories was supplied by an increase of carbohydrates with normal fat content (Bioserv, Frenchtown, NJ, USA). The detailed composition of this diet has been published previously (Snoeck et al. 1990, Desai et al. 1996, Boujendar et al. 2003). At birth, litter size was restricted to eight rats (four males and four females) with weights closest to the litter mean in order to maintain equal growth (Boujendar et al. 2002, 2003). Any mother that had less than eight offspring in her litter was excluded from the study. Six to eight litters per group were used, and one male and one female per litter were studied. The rats were maintained at $12 \mathrm{~h}$ light: $12 \mathrm{~h}$ darkness cycles and were given free access to food and water. Body weight was monitored throughout until 130 days of age. The Animal Care Committees of the University of Western Ontario and the University of Toronto approved all the procedures.

\section{Surgery}

At 130 days of age, offspring were cannulated as described previously (Mason et al. 1999, Chintoh et al. 2009). The jugular catheter was used for infusion and the carotid catheter for 
blood sampling. The rats were allowed at least 3 days of postsurgery recovery before conducting the clamp studies.

\section{Hyperinsulinemic-euglycemic clamp}

Hyperinsulinemic-euglycemic clamp was performed in $\sim 18$-h overnight fasted rats. The rats were injected with a bolus of $8 \mu \mathrm{Ci}\left[3-{ }^{3} \mathrm{H}\right]$ glucose, and this was followed by a constant infusion at $0.15 \mu \mathrm{Ci} / \mathrm{min}$ (Perkin-Elmer, Boston, MA, USA) for $90 \mathrm{~min}$. Thereafter, the hyperinsulinemic-euglycemic clamp was performed for $90 \mathrm{~min}$. During the $30 \mathrm{~min}$ preceding the clamp ('basal period'), measurements were taken at 10-min intervals for plasma glucose, insulin, and $\left[3-{ }^{3} \mathrm{H}\right]$ glucosespecific activity. At the onset of the clamp, a continuous infusion of porcine insulin at $5 \mathrm{mU} / \mathrm{kg}$ per min was started, resulting in plasma insulin levels in the postprandial range. To maintain euglycemia during insulin infusion, a variable infusion of $20 \%$ glucose was given through the jugular catheter and adjusted according to glycemic determinations every $5 \mathrm{~min}$. The glucose infusate was radiolabeled with $48 \mu \mathrm{Ci} / \mathrm{g}$ $\left[3-{ }^{3} \mathrm{H}\right]$ glucose to maintain the plasma glucose-specific activity constant. After plasma separation, red blood cells were diluted at a 1:1 ratio in heparinized saline $(4 \mathrm{U} / \mathrm{ml})$ and re-infused into the rats.

At the end of the hyperinsulinemic-euglycemic clamp, the rats were allowed to recover for $120 \mathrm{~min}$. Ginf was continued for another $30 \mathrm{~min}$ after insulin infusion was stopped to prevent hypoglycemia associated with residual insulin actions following the clamp.

\section{Hyperglycemic clamp}

Following the recovery period, a hyperglycemic clamp (17 mM glucose) was performed for $90 \mathrm{~min}$. Basal insulin and C-peptide levels were measured at -10 and 0 min before the start of the hyperglycemic clamp. At time 0 , a glucose bolus ( $50 \%$ dextrose: $0.1 \%$ of body weight) followed by a continuous infusion of $37.5 \%$ glucose was given. Plasma glucose level was maintained at $17 \mathrm{mM}$ by adjusting the rate of Ginf according to frequent (5 min) glycemic determinations. Plasma samples for insulin and C-peptide measurements were taken at regular intervals to assess both first-phase and second-phase insulin secretion. After plasma separation, red blood cells were diluted at a $1: 1$ ratio in heparinized saline $(4 \mathrm{U} / \mathrm{ml})$ and re-infused into the rats.

\section{Plasma assays}

Plasma glucose was measured using a Beckman Analyzer II (Fullerton, CA, USA). Plasma radioactivity from $\left[3-{ }^{3} \mathrm{H}\right]$ glucose was determined after deproteinization with $\mathrm{Ba}(\mathrm{OH})_{2}$ and $\mathrm{ZnSO}_{4}$ and subsequent evaporation to dryness. The aliquots of $\left[3-{ }^{3} \mathrm{H}\right]$ glucose and tritiated glucose infusate were assayed together with the plasma samples (Lam et al. 2002). Plasma insulin and C-peptide levels were measured using Linco's RIA kits (St Charles, MO, USA), specific for rat insulin (but with $100 \%$ cross-reactivity with porcine insulin used for infusion) and C-peptide respectively.

\section{Calculations}

EGP and glucose utilization during the basal period and the hyperinsulinemic-euglycemic clamp were calculated by standard tracer methods (Steele et al. 1956, Finegood et al. 1987). Data are presented as average values of the samples that were taken during the $30 \mathrm{~min}$ preceding the clamp and during the last $30 \mathrm{~min}$ of the clamp.

\section{Insulin sensitivity}

The $M / I$ index of insulin sensitivity (De Fronzo et al. 1979) was calculated by dividing the Ginf rate by the plasma insulin level during the last $30 \mathrm{~min}$ of the hyperinsulinemiceuglycemic clamp.

\section{$\beta$-Cell function}

$\beta$-Cell function in vivo was assessed by taking into account insulin sensitivity, since the normal $\beta$-cell compensates for insulin resistance. This was done by calculating the DI, which represents the hyperbolic relationship between insulin secretion and insulin sensitivity in normal subjects (Kahn et al. 1993, Bergman et al. 2002). In humans, this index is calculated as a product (a constant) of insulin secretion and insulin sensitivity (Kahn et al. 1993, Bergman et al. 2002). In rats, insulin secretion rate cannot be calculated because their C-peptide kinetics has not been determined (the specific rat $\mathrm{C}$-peptide is unavailable for injection). Thus, we used the C-peptide levels as an approximation of insulin secretion rate as in our earlier studies (Goh et al. 2007). Previously, we showed a hyperbolic relationship between the $M / I$ index and the C-peptide levels during the hyperglycemic clamp in rats (Goh et al. 2007). The DI was calculated by multiplying the average last 30-min $\mathrm{M} / \mathrm{I}$ index (from the hyperinsulinemiceuglycemic clamp) by the C-peptide levels during the hyperglycemic clamp.

\section{Statistical analysis}

All analyses were conducted using either a two-way (sex and treatment) or a one-way ANOVA for repeated measurements. Post hoc Tukey's tests were conducted when significant effects were observed following an ANOVA or Mann-Whitney $U$ tests following a Kruskal-Wallis test. Data analyses were conducted with the PASW version 18 (IBM, Chicago IL, USA, 2009) and SAS version $\mathrm{xx}$ (Cary, NC, USA). Data are presented as means \pm S.E.M.

\section{Supplementary data}

This is linked to the online version of the paper at http://dx.doi. org/10.1530/REP-12-0388.

\section{Declaration of interest}

The authors declare that there is no conflict of interest that could be perceived as prejudicing the impartiality of the research reported. 


\section{Funding}

This study was funded by grants from Dairy Farmers of Canada to Dr E Arany and grants from Canadian Institute of Health Research (MOP\#89929 and 69018) to Dr A Giacca. Ms C Tang was supported by Banting and Best Diabetes-Novo Nordisk award (University of Toronto) Ontario Graduate Scholarship and Canada Graduate Scholarship.

\section{References}

Arany E, Strutt B, Romanus P, Remacle C, Reusens B \& Hill DJ 2004 Taurine supplement in early life altered islet morphology, decreased insulitis and delayed the onset of diabetes in non-obese diabetic mice. Diabetologia 47 1831-1837. (doi:10.1007/s00125-004-1535-z)

Bergman RN, Phillips LS \& Cobelli C 1981 Physiologic evaluation of factors controlling glucose tolerance in man: measurement of insulin sensitivity and $\beta$-cell glucose sensitivity from the response to intravenous glucose. Journal of Clinical Investigation 68 1456-1467. (doi:10.1172/ JCI110398)

Bergman RN, Ader M, Huecking K \& Van Citters G 2002 Accurate assessment of $\beta$-cell function: the hyperbolic correction. Diabetes $\mathbf{5 1}$ (Suppl 1) S212-S220. (doi:10.2337/diabetes.51.2007.S212)

Bouckenooghe T, Remacle C \& Reusens B 2006 Is taurine a functional nutrient? Current Opinion in Clinical Nutrition and Metabolic Care 9 728-733. (doi:10.1097/01.mco.0000247469.26414.55)

Boujendar S, Reusens B, Merezak S, Ahn MT, Arany E, Hill D \& Remacle C 2002 Taurine supplementation to a low protein diet during foetal and early postnatal life restores a normal proliferation and apoptosis of rat pancreatic islets. Diabetologia 45 856-866. (doi:10.1007/s00125-0020833-6)

Boujendar S, Arany E, Hill D, Remacle C \& Reusens B 2003 Taurine supplementation of a low protein diet fed to rat dams normalizes the vascularization of the fetal endocrine pancreas. Journal of Nutrition 133 2820-2825.

Chamson-Reig A, Thyssen SM, Hill DJ \& Arany E 2009 Exposure of the pregnant rat to low protein diet causes impaired glucose homeostasis in the young adult offspring by different mechanisms in males and females. Experimental Biology and Medicine 234 1425-1436. (doi:10.3181/ 0902-RM-69)

Cherif H, Reusens B, Ahn MT, Hoet JJ \& Remacle C 1998 Effects of taurine on the insulin secretion of rat fetal islets from dams fed a low-protein diet. Journal of Endocrinology 159 341-348. (doi:10.1677/joe.0.1590341)

Chintoh AF, Mann SW, Lam L, Giacca A, Fletcher P, Nobrega J \& Remington G 2009 Insulin resistance and secretion in vivo: effects of different antipsychotics in an animal model. Schizophrenia Research 108 127-133. (doi:10.1016/j.schres.2008.12.012)

Dahri S, Snoeck A, Reusens-Billen B, Remacle C \& Hoet JJ 1991 Islet function in offspring of mothers on low-protein diet during gestation. Diabetes 40 (Suppl 2) 115-120.

Dahri S, Reusens B, Remacle C \& Hoet JJ 1995 Nutritional influences on pancreatic development and potential links with non-insulindependent diabetes. Proceedings of the Nutrition Society 54 345-356. (doi:10.1079/PNS19950003)

De Fronzo RA, Tobin JD \& Andres R 1979 Glucose clamp technique: a method quantifying insulin secretion and resistance. American Journal of Physiology 237 E214-E223.

Desai M, Growther NJ, Lucas A \& Hales CN 1996 Organ-selective growth in the offspring of protein-restricted mothers. British Journal of Nutrition 76 591-603. (doi:10.1079/BJN19960065)

Desai M, Byrne CD, Zhang J, Petry CJ, Lucas A \& Hales CN 1997 Programming of hepatic insulin-sensitive enzymes in offspring of rat dams fed a protein-restricted diet. American Journal of Physiology 272 G1083-G1090.

Durst MA, Lux-Lantos VA, Hardy DB, Hill DJ \& Arany EJ 2012 Protein restriction during early life in rats alters pancreatic GABAa receptor subunit expression and glucagon secretion in adulthood. Canadian Journal of Diabetes 36 100-107. (doi:10.1016/j.jcjd.2012.06.002)
Evans JL, Goldfine ID, Maddux BA \& Grodsky GM 2003 Are oxidative stress-activated signaling pathways mediators of insulin resistance and B-cell dysfunction? Diabetes 52 1-8. (doi:10.2337/diabetes.52.1.1)

Fernandez-Twinn DS, Wayman A, Ekizoglou S, Martin MS, Hales CN \& Ozanne SE 2005 Maternal protein restriction leads to hyperinsulinemia and reduced insulin-signaling protein expression in 21-mo-old female rat offspring. American Journal of Physiology. Regulatory, Integrative and Comparative Physiology 288 R368-R373. (doi:10.1152/ajpregu. 00206.2004)

Finegood DT, Bergman RN \& Vranic M 1987 Estimation of endogenous glucose production during hyperinsulinemic-euglycemic glucose clamps. Comparison of unlabeled and labeled exogenous glucose infusates. Diabetes 36 914-924. (doi:10.2337/diabetes.36.8.914)

Forsen T, Eriksson J, Tuomilehto J, Reunanen A, Osmond C \& Barker D 2000 The fetal and childhood growth of persons who develop type 2 diabetes. Annals of Internal Medicine 133 176-182. (doi:10.7326/00034819-133-3-200008010-00008)

Fortman J II, Reichling T \& German RZ 2005 The impact of maternal protein malnutrition on pre-weaning skeletal and visceral organ growth in neonatal offspring of Rattus norvegicus. Growth, Development, and Aging 69 39-52.

Garcia-Souza EP, da Silva SV, Felix GB, Rodrigues AL, de Freitas MS, Moura AS \& Barja-Fidalgo C 2008 Maternal protein restriction during early lactation induces GLUT4 translocation and mTOR/Akt activation in adipocytes of adult rats. American Journal of Physiology. Endocrinology and Metabolism 295 E626-E636. (doi:10.1152/ajpendo.00439.2007)

Gluckman PD \& Hanson MA 2006 The consequences of being born small - an adaptive perspective. Hormone Research 65 (Suppl 3) 5-14. (doi:10.1159/000091500)

Goh TT, Mason TM, Gupta N, So A, Lam TK, Lam L, Lewis GF, Mari A \& Giacca A 2007 Lipid-induced $\beta$-cell dysfunction in vivo in models of progressive $\beta$-cell failure. American Journal of Physiology. Endocrinology and Metabolism 292 E549-E560. (doi:10.1152/ajpendo.00255.2006)

Hales CN \& Barker DJ 1992 Type 2 (non-insulin-dependent) diabetes mellitus: the thrifty phenotype hypothesis. Diabetologia 35 595-601. (doi:10.1007/BF00400248)

Hales CN \& Barker DJ 2001 The thrifty phenotype hypothesis. British Medical Bulletin 60 5-20. (doi:10.1093/bmb/60.1.5)

Han J, Bae JH, Kim SY, Lee HY, Jang BC, Lee IK, Cho CH, Lim JG, Suh SI, Kwon TK et al. 2004 Taurine increases glucose sensitivity of UCP2-overexpressing $\beta$-cells by ameliorating mitochondrial metabolism. American Journal of Physiology. Endocrinology and Metabolism 287 E1008-E1018. (doi:10.1152/ajpendo.00008.2004)

Hansen SH 2001 The role of taurine in diabetes and the development of diabetic complications. Diabetes/Metabolism Research and Reviews 17 330-346. (doi:10.1002/dmrr.229)

Hojlund K, Mogensen M, Sahlin K \& Beck-Nielsen H 2008 Mitochondrial dysfunction in type 2 diabetes and obesity. Endocrinology and Metabolism Clinics of North America 37 713-731, x. (doi:10.1016/ j.ecl.2008.06.006)

Hotamisligil GS 2006 Inflammation and metabolic disorders. Nature $\mathbf{4 4 4}$ 860-867. (doi:10.1038/nature05485)

Huxtable RJ 1992 Physiological actions of taurine. Physiological Reviews 72 101-163.

Kahn SE, Prigeon RL, McCulloch DK, Boyko EJ, Bergman RN, Schwartz MW, Neifing JL, Ward WK, Beard JC \& Palmer JP 1993 Quantification of the relationship between insulin sensitivity and $\beta$-cell function in human subjects. Evidence for a hyperbolic function. Diabetes 42 1663-1672. (doi:10.2337/diabetes.42.11.1663)

Lam TK, Yoshii H, Haber CA, Bogdanovic E, Lam L, Fantus IG \& Giacca A 2002 Free fatty acid-induced hepatic insulin resistance: a potential role for protein kinase C- $\delta$. American Journal of Physiology. Endocrinology and Metabolism 283 E682-E691. (doi:10.1154/ajendo.00038.2002)

Lee YY, Lee HJ, Lee SS, Koh JS, Jin CJ, Park SH, Yi KH, Park KS \& Lee HK 2011 Taurine supplementation restored the changes in pancreatic islet mitochondria in the fetal protein-malnourished rat. British Journal of Nutrition 106 1198-1206. (doi:10.1017/S0007114511001632)

Lourenco R \& Camilo ME 2002 Taurine: a conditionally essential amino acid in humans? An overview in health and disease Nutrición Hospitalaria 17 262-270. 
Mason TM, Goh T, Tchipashvili V, Sandhu H, Gupta N, Lewis GF \& Giacca A 1999 Prolonged elevation of plasma free fatty acids desensitizes the insulin secretory response to glucose in vivo in rats. Diabetes 48 524-530. (doi:10.2337/diabetes.48.3.524)

Merezak S, Hardikar AA, Yajnik CS, Remacle C \& Reusens B 2001 Intrauterine low protein diet increases fetal $\beta$-cell sensitivity to $\mathrm{NO}$ and IL-1 $\beta$ : the protective role of taurine. Journal of Endocrinology 171 299-308. (doi:10.1677/joe.0.1710299)

Merezak S, Reusens B, Renard A, Goosse K, Kalbe L, Ahn MT, Tamarit-Rodriguez J \& Remacle C 2004 Effect of maternal lowprotein diet and taurine on the vulnerability of adult Wistar rat islets to cytokines. Diabetologia 47 669-675. (doi:10.1007/s00125-004-1357-z)

Minana-Solis Mdel C \& Escobar C 2008 Post-weaning protein malnutrition in the rat produces short and long term metabolic impairment, in contrast to earlier and later periods. International Journal of Biological Sciences $\mathbf{4}$ 422-432. (doi:10.7150/ijbs.4.422)

Oprescu AI, Bikopoulos G, Naassan A, Allister EM, Tang C, Park E, Uchino H, Lewis GF, Fantus IG, Rozakis-Adcock M et al. 2007 Free fatty acid-induced reduction in glucose stimulated insulin secretion evidence for a role of oxidative stress in vitro and in vivo. Diabetes 56 2027-2937. (doi:10.2337/db07-0075)

Ozanne SE, Wang CL, Coleman N \& Smith GD 1996 Altered muscle insulin sensitivity in the male offspring of protein-malnourished rats. American Journal of Physiology 271 E1128-E1134.

Ozanne SE, Nave BT, Wang CL, Shepherd PR, Prins J \& Smith GD 1997 Poor fetal nutrition causes long-term changes in expression of insulin signaling components in adipocytes. American Journal of Physiology 273 E46-E51.

Ozanne SE, Olsen GS, Hansen LL, Tingey KJ, Nave BT, Wang CL, Hartil K, Petry CJ, Buckley AJ \& Mosthaf-Seedorf L 2003 Early growth restriction leads to down regulation of protein kinase $C \zeta$ and insulin resistance in skeletal muscle. Journal of Endocrinology 177 235-241. (doi:10.1677/ joe.0.1770235)

Petrik J, Reusens B, Arany E, Remacle C, Coelho C, Hoet JJ \& Hill DJ 1999 A low protein diet alters the balance of islet cell replication and apoptosis in the fetal and neonatal rat and is associated with a reduced pancreatic expression of insulin-like growth factor-II. Endocrinology 140 4861-4873. (doi:10.1210/en.140.10.4861)

Rehfeldt C, Lefaucheur L, Block J, Stabenow B, Pfuhl R, Otten W, Metges CC \& Kalbe C 2012 Limited and excess protein intake of pregnant gilts differently affects body composition and cellularity of skeletal muscle and subcutaneous adipose tissue of newborn and weanling piglets. European Journal of Nutrition 51 151-165. (doi:10.1007/s00394-0110201-8)

Reusens BDS, Snoek A, Bennis-Taleb N, Remacle C \& Hoett JJ 1995 Long-term consequences of diabetes and its complications may have a fetal origin: experimental and epidemiological evidence. In Diabetes. Nestle: Workshop Series, 25, pp 187-188. Ed. RM Edit Cowett. New York: Raven Press.

Sandovici I, Smith NH, Nitert MD, Ackers-Johnson M, Uribe-Lewis S, Ito Y, Jones RH, Marquez VE, Cairns W, Tadayyon M et al. 2011 Maternal diet and aging alter the epigenetic control of a promoter-enhancer interaction at the Hnf4a gene in rat pancreatic islets. PNAS 108 5449-5454. (doi:10.1073/pnas.1019007108)

Shaw JE, Sicree RA \& Zimmet PZ 2010 Global estimates of the prevalence of diabetes for 2010 and 2030. Diabetes Research and Clinical Practice 87 4-14. (doi:10.1016/j.diabres.2009.10.007)

Shepherd PR, Crowther NJ, Desai M, Hales CN \& Ozanne SE 1997 Altered adipocyte properties in the offspring of protein malnourished rats. British Journal of Nutrition 78 121-129. (doi:10.1079/BJN19970124)

Snoeck A, Remacle C, Reusens B \& Hoet JJ 1990 Effect of a low protein diet during pregnancy on the fetal rat endocrine pancreas. Biology of the Neonate 57 107-118. (doi:10.1159/000243170)

Steele R, Wall JS, De Bodo RC \& Altszuler N 1956 Measurement of size and turnover rate of body glucose pool by the isotope dilution method. American Journal of Physiology 187 15-24.

Sturman JA 1993 Taurine in development. Physiological Reviews 73 119-147.

Sugden MC \& Holness MJ 2002 Gender-specific programming of insulin secretion and action. Journal of Endocrinology 175 757-767. (doi:10.1677/joe.0.1750757)

Suzuki T, Wada T, Saigo K \& Watanabe K 2002 Taurine as a constituent of mitochondrial tRNAs: new insights into the functions of taurine and human mitochondrial diseases. EMBO Journal 21 6581-6589. (doi:10.1093/emboj/cdf656)

Tang C, Han P, Oprescu AI, Lee SC, Gyulkhandanyan AV, Chan GN, Wheeler MB \& Giacca A 2007 Evidence for a role of superoxide generation in glucose-induced $\beta$-cell dysfunction in vivo. Diabetes $\mathbf{5 6}$ 2722-2731. (doi:10.2337/db07-0279)

Zambrano E, Bautista CJ, Deas M, Martinez-Samayoa PM, GonzalezZamorano M, Ledesma H, Morales J, Larrea F \& Nathanielsz PW 2006 A low maternal protein diet during pregnancy and lactation has sex- and window of exposure-specific effects on offspring growth and food intake, glucose metabolism and serum leptin in the rat. Journal of Physiology 571 221-230. (doi:10.1113/jphysiol.2005.100313)

Received 2 October 2012

First decision 29 October 2012

Revised manuscript received 15 April 2013

Accepted 22 April 2013 